\title{
A ESTRUTURA DO XILEMA SECUNDÁRIO DE Mimosa daleoides Benth. (LEGUMINOSAE MIMOSOIDEAE).
}

Josē Newton Cardoso Marchiori

Departamento de Ciências Florestais. Centro de Ciências Rurais. UFSM. Santa Maria, RS.

\section{RESUMO}

São descritos os caracteres gerais, macnoscópicos e micros cōpicos da madeira de Mimosa daleoides Benth. São fornecidos dados quantitativos e histométricos do xilema secundārio e ilustrações da madeira.

0 xilema secundário deste arbusto é comparado com o de outras espēcies de madeira do mesmo gênero.

SUMMARY

MARCHIORI,J.N.C., 1982. The secondary xylem structure of Mimosa da Zeoides Benth. (Leguminosae Mimosoideae). Ciência e Natura (4):107-113.

The gross, macroscopic and microscopic wood structure of Mimosa daleoides Benth. (Leguminosae Mimosoideae) are described.

Aside from quantitative and histometric data from the secon dary xylem, illustrations of wood are furnished.

The secondary xylem of this shrub is compared with other wood species of the same genus.

INTRODU ÇĀO

0 gēnero Mimosa L. compreende cerca de 400 espécies, nati vas principalmente na Amērica tropical e subtropical. Em sua maior parte são ervas e arbustos, sendo raras as espécies arbōreas (BUR KART, 3).

Na flora sul-brasileira são numerosas as espēcies de Mimosa. RAMBO (9) cita 53 espécies para o Rio Grande do Sul, e BURKART (5), 48 para o Estado de Santa Catarina. A maioria destas espécies são plantas de pequeno porte e de utilização desconhecida. Apenas Mimosa scabrezza e $M$. bimucronata são cultivadas para a produção de madeira e lenha (BURKART, 4).

A utilização limitada das espécies de Mimosa não estimulou a realização de estudos anatômicos. Poucos são as espēcies deste gê nero, para as quais foram descritos os caracteres gerais, macroscó picos e microscōpicos da madeira.

RECORD \& HESS (10) citam caracteres gerais e organolēpticos para as madeiras do gênero Mimosa. Estas informações, entretanto, 
foram baseadas em apenas duas espécies.

cozzo (7) comparou a estrutura de 11 madeiras de Mimosa na tivas da Argentina, com vistas à identificação e taxonomia. Este au tor verificou uma ampla variação anatōmica entre as espécies exami nadas, não encontrando um carāter comum às mesmas. Segundo Cozzo, 0 gēnero Mimosa é estruturalmente heterogêneo.

MARCHIORI (8) descreveu a anatomia da madeira e da casca de Mimosa scabrezza e Mimosa bimucronata. Comparando a estrutura destas madeiras com a de outras duas espécies do mesmo gênero, este autor constatou que as espécies da secção Eumimosa Benth. se assemelhan pe la estratificação do parênquima axial e elementos vasculares, e for ma das células radiais em plano longitudinal tangencial. 0 mesmo au tor, por outro lado, encontrou diferenças marcantes quanto a estes mesmos caracteres na madeira de $M$. bimucronata, da secção Habbasia Benth. Ressalta, entretanto, que a utilização de um carāter anatōmi co para fins taxonōmicos requer um estudo mais profundo, com um maior nūmero de espēcies.

A madeira estudada neste trabalho ē desconhecida anatomi camente.

Mimosa daleoides Benth. é um arbusto pequeno, de 1 a $2 \mathrm{~m}$ de altura, nativo do Brasil sul-oriental, desde São Paulo atē o Rio Grande do Sul, nordeste da Aegentina, Paraguai e Bolívia. E espécie heliōfila e seletiva xerófila, sendo muito frequente em campos de so los enxutos e rochosos onde costuma formar densos agrupamentos. Por ser muito semelhante à bracaatinga quando jovem, esta espécie é co nhecida comumente por bracaatinga-miūda (BURKART, 5).

MATERIAL E METODOS

A amostra de madeira estudada ē procedente do município de Santiago, RS, e se encontra registrada no Herbārio do Departamen to de Ciências Florestais da UFSM (HDCF) com o nọ 580.

As secções anatōmicas foram coloridas com safranina e azul de astra, e montadas em lâminas permanentes com "Entellan".

A maceração da madeira foi feita pelo mētodo de Jeffrey, sendo o tecido macerado colorido com safranina.

Para as descrições seguiu-se a Norma COPANT (6), com as alterações propostas por BURGER (2). Os dados quantitativos da estru tura anatōmica da madeira são apresentados na Tabela I.

As fotomicrografias foram realizadas em fotomicroscōpio Carl Zeiss. O cartão perfurado, com características da madeira e espécie, foi preenchido conforme BRAZIER \& FRANKLIN (1), e ē apre sentado na Figura 2. 
TABELA I. DADOS QUANTITATIVOS DA ESTRUTURA ANATOMMICA DO XILEMA SECUN DARIO DE Mimosa daleoides Benth.

\begin{tabular}{|c|c|c|c|c|}
\hline CARACTERISTICA & $\begin{array}{l}\text { VALOR } \\
\text { MIN. }\end{array}$ & MEDI A & $\begin{array}{l}\text { VALOR } \\
\text { MAX. }\end{array}$ & $\begin{array}{l}\text { DESVIO } \\
\text { PADRAO }\end{array}$ \\
\hline 1. Poros $/ \mathrm{mm}^{2}$ & 32 & 51 & 62 & 3,5 \\
\hline 2. $\emptyset$ tangencial de poros $(\mu \mathrm{m})$ & 42,5 & 67,2 & 85 & 9,6 \\
\hline 3. C. elementos vasculares $(\mu \mathrm{m})$ & 165 & 247,8 & 313 & 33,0 \\
\hline $\begin{array}{l}\text { 4. C. de apêndices de elementos } \\
\text { vasculares }(\mu \mathrm{m})\end{array}$ & 10 & 28,4 & 63 & 14,3 \\
\hline 5. Fração de poros $(\%)$ & 8 & 9,33 & 12 & 1,36 \\
\hline 6. Fração de parênquima axial (\%) & 16 & 17,5 & 20 & 1,64 \\
\hline 7. C. das séries de parênquima $(\mu \mathrm{m})$ & 230 & 271,2 & 363 & 36,7 \\
\hline $\begin{array}{l}\text { 8. C. das células de parênquima axial } \\
\text { seriado }(\mu \mathrm{m})\end{array}$ & 100 & 135,6 & 187,5 & 20,2 \\
\hline 9. Fração de tecido radial (\%) & 18 & 20 & 23 & 2,1 \\
\hline 10. Raios/mm & 7 & 9,64 & 13 & 1,32 \\
\hline 11. H. raios uni-seriados $(\mu \mathrm{m})$ & 55 & 164,7 & 425 & 78,9 \\
\hline 12. H. raios uni-seriados (células) & 2 & 6,28 & 14 & 2,88 \\
\hline 13. L. raios uni-seriados $(\mu \mathrm{m})$ & 10 & 13,5 & 20 & 2,53 \\
\hline 14. H. raios multi-seriados ( $\mu \mathrm{m})$ & 182,5 & 769,7 & 2017,5 & 419,3 \\
\hline 15. H. raios multi-seriados (células) & 7 & 34,5 & 95 & 20,11 \\
\hline 16. L. raios multi-seriados $(\mu \mathrm{m})$ & 17,5 & 26,8 & 47,5 & 5,03 \\
\hline 17. L. raios multi-seriados (células) & 2 & 2,76 & 4 & 0,59 \\
\hline 18. Fração de fibras (\%) & 49 & 53,16 & 57 & 3,19 \\
\hline 19. Comprimento de fibras $(\mu \mathrm{m})$ & 420 & 614,7 & 840 & 78,6 \\
\hline 20. $\emptyset$ total de fibras $(\mu \mathrm{m})$ & 12,5 & 17,7 & 25 & 2,31 \\
\hline 21. $\emptyset$ do lumem de fibras $(\mu \mathrm{m})$ & 5 & 8,65 & 12,5 & 1,97 \\
\hline
\end{tabular}

DESCRIÇAO DA MADEIRA

CARACTERES GERAIS E ORGANOLEPTICOS

Madeira de cerne e alburno indistintos, sem brilho, de cor creme ou palha, de grã direita, macia, de textura fina e sem odor e gos to característicos.

\section{CARACTERES MACROSCOPICOS}

Poros: Invisíveis a olho nu, visĩveis sob lente de 10x, em distri buição difusa; solitārios e, menos frequentemente, em mưltiplos ra diais de 2 ou 3 poros; pequenos, muito numerosos, com conteúdos, e com placa de perfuração simples. Linhas vasculares retilineas.

Parênquima axial: Visivel em plano transversal apenas sob lente de 10 aumentos; paratraqueal vasicêntrico, escasso. 
Parênquima radial: Raios invisíveis a olho nu em plano transversal, finos, pouco frequentes. Em secção longitudinal tangencial, visiveis com dificuldade sob lente, baixos, não estratificados. Espelhadodos raios pouco contrastado.

Anéis de crescimento: Distintos a otho nu, individualizados por zo nas fibrosas tangenciais mais escuras.

outros caracteres: Canais secretores axiais, máculas medulares e if ber incluso, ausentes.

CARACTERES MICROSCOPICOS

Vasos: Porosidade difusa, uniforme (Figura 1 a). Poros de secção cir cular a oval, pequenos (43-67-85 $\mu \mathrm{m}$ de diâmetro tangencial), de muito numerosos a numerosissimos $\left(32-51-62\right.$ poros $\left./ \mathrm{mm}^{2}\right)$, ocupando cerca de $9,3 \%$ do volume da madeira; solitários, geminados, menos fre quentemente em agrupamentos radiais e racemiformes de 3 a 5 poros.

Elementos vasculares muito curtos $(165-248-313 \mu \mathrm{m})$, de paredes espessas, não ornamentadas, com placa de perfuração simples e com apēndices curtos $(10-28-63 \mu \mathrm{m})$ presentes em uma ou em am bas extremidades. Pontuado intervascular alterno. Pontuações inter vasculares pequenas, de forma oval, guarnecidas; com abertura hori zontal, lenticular, inclusa ou coalescente atē a 3 pontuações. Pon tuações parēnquimo-vasculares e rādio-vasculares semelhantes às pon tuações intervasculares; pequenas e arredondadas, menores de $10 \mu \mathrm{m}$. Traqueóides vasicêntricos, traqueóides vasculares e elementos vascu Tares imperfeitos, ausentes.

Parênquima axiaz: Pouco abundante, ocupando cerca de $17,5 \%$ do volu me da madeira; dos tipos paratraqueal unilateral e vasicêntrico. Cé 1 ulas de parênquima axial com $100-136-188 \mu \mathrm{m}$ de altura, em sé ries verticais estratificadas em plano radial. Séries de parênquima axial com 230 - 271 - $363 \mu \mathrm{m}$ de altura e com 2 células por sērie.

Parênquima radial: Tecido radial fracamente heterogêneo, composto principalmente de cēlulas horizontais (Figura 1 b). Raios ocupando cerca de $20 \%$ do volume da madeira, numerosos (7 - 9 - 13 raios $/ \mathrm{mm}$ ). Raios de tipo normal; raios agregados e fusionados, ausentes (Figu ra $1 \mathrm{c})$.

Raios uni-seriados pouco frequentes ( $16 \%$ dos raios), de baixos a medianos $(55-165-425 \mu \mathrm{m})$, extremamente finos (10 $13,5-20 \mu \mathrm{m})$ e com $2-6$ - 15 cé lulas de altura.

Raios multi-seriados, principalmente tri-seriados ( $45 \%$ dos raios), mebos frequentemente bi e tetra-seriados (cerca de $19 \%$ para cada tipo). Raios multi-seriados muito baixos (182 - $770-2018$ $\mu \mathrm{m})$, com $7-35-95$ células de altura, e muito finos $(17,5-27-48 \mu \mathrm{m})$. 


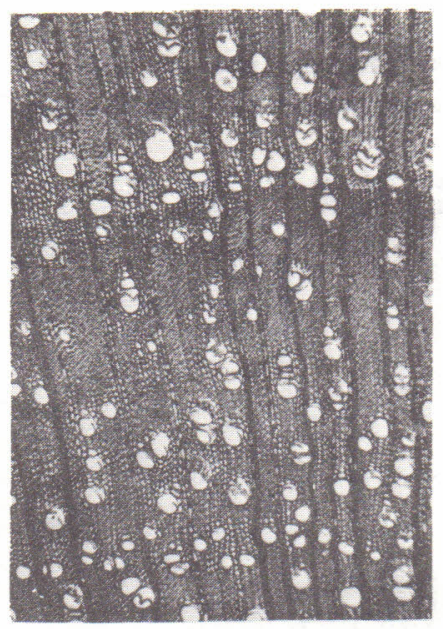

a

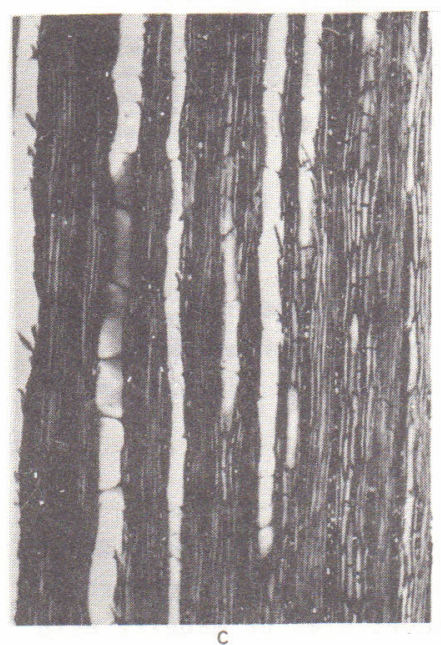

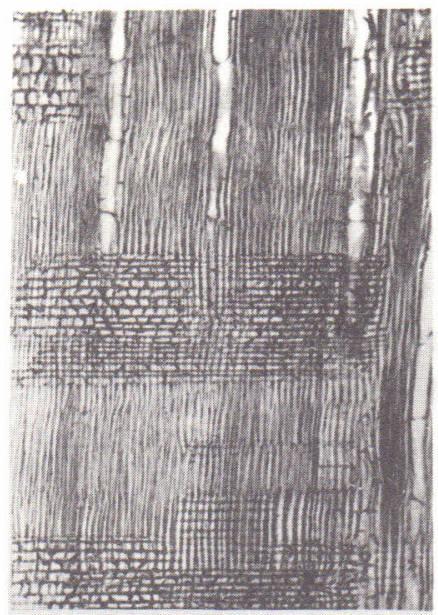

b

Figura 1. Fotografias da madeira de Mimosa dazeoides Benth. a, Secção trans versal $1(50 x)$. b, Secção 1 ongitudinal radial(50X). c, Secção longitudinal tangencial (50x).

Fibras: Tecido fibroso proeminente, ocupando cerca de $53 \%$ do volume da madeira. Fibras libriformes não septadas, frequentemente gelati nosas; dotadas de pontuações simples, diminutas, mais abundantes na face radial da parede celular.

Fibras extremamente curtas $(420-615-840 \mu \mathrm{m})$ e de pare des delgadas.

Outros caracteres: Canais secretores, tubos lacticíferos e taninífe ros, liber incluso e māculas medulares, não foram observados. Anéis de crescimento distintos, evidenciados pela concentração de fibras 
de paredes mais espessas no lenho tardio.

Inclusões orgânicas com o aspecto de goma, mas de nature za quĩmica não determinada neste trabalho, encontram-se presentes em poros do cerne.

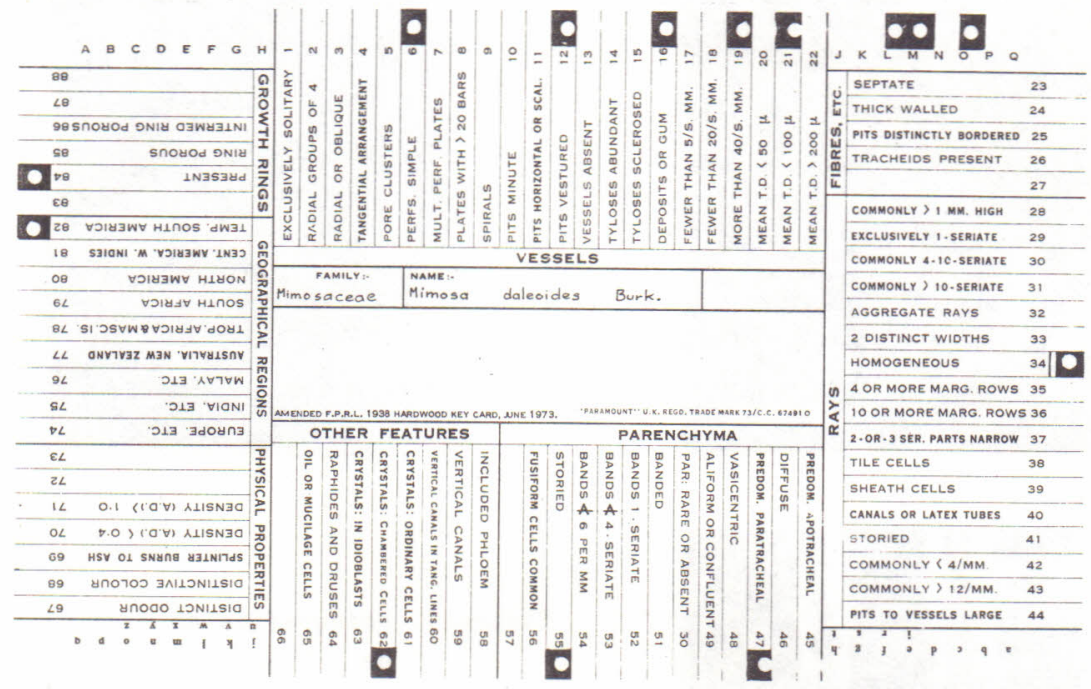

Figura 2. Cartão perfurado das principais características da madeira de Mimosa daleoides Benth.

Inclusões inorgânicas são muito pouco frequentes, aparecen do na forma de cristais romböides de oxalato de cálcio em séries cris talîferas de parênquima axial e, menos comumente, em cēlulas margị nais de parēnquima radial.

\section{ANALLISE DA ESTRUTURA ANATÔMICA DA MADEIRA}

Os caracteres gerais da madeira de Mimosa daleoides Benth. correspondem com a descrição de RECORD \& HESS (10) para o gênero.

Os caracteres anatômicos mais importantes na madeira estu dada, tais como a presença de elementos vasculares muito curtos e com placa de perfuração simples, pontuações intervasculares peque nas, parênquima axial dos tipos paratraqueal unilateral e vasicêntri co, fibras libriformes curtas e raios praticamente homogêneos, são, entretanto, caracteres comuns à maioria das madeiras de Leguminosae Mimosoideae.

A nível microscópico cozzo (7) observou uma ampla variação anatômica entre as espēcies de Mimosa por ele estudadas. Este autor considera, por este motivo, o gênero Mimosa como estruturalmente he terogêneo. Cozzo ressalta a existência de grande variação quanto ao 
tipo de porosidade e altura de raios, tipo de células parênquimati cas radiais, abundância de parênquima axial, e presença ou não de septos em fibras e de estratificação na madeira.

MARCHIORI (8) encontrou semelhança anatômica entre 3 espé cies da secção Eumimosa Benth., e diferenças entre estas e Mimosa bimucronata, pertencente à secção Habbasia do mesmo gênero. No mes mo trabalho, o autor sugere que a presença de células parênquimati cas radiais altas e de estratificação do parênquima axial em plano longitudinal radial, tenham valor taxonōmico para a secção Eumimosa.

A estrutura anatōmica de Mimosa dazeoides Benth., descri ta neste trabalho, assemelha-se quanto a estes aspectos às referidas espēcies da secção Eumimosa estudadas por MARCH.IORI (8).

\section{REFERENCIAS BIBLIOGRAFICAS}

1. BRAZIER,J.D. \& FRANKLIN,G.L. Identification of Hardwoods - a microscope Key. For. Prod. Res. B., London, 1961. 196 p.

2. BURGER,L.M. Estudo anatômico do xilema secundärio de sete espé cies nativas do gênero Dalbergia - Leguminosae Faboideas.Curi tiba, UFPr. $184 \mathrm{f}$. Tese de Mestrado.

3. BURKART, A. Las Leguminosas argentinas silvestres y cultivadas.Bue nos Aires, ACME, 1952. 569 p.

4. BURKART, A. Leguminosae. In: PARODI,L.R. Enciclopedia argentina de Agricultura y Jardineria. Buenos Aires, ACME. 1959. V. 1: 443-512.

5. BURKART, A. Leguminosas Mimosoideas. Flora IZustrada Catarinense, 1979. $299 \mathrm{P}$.

6. COMISSION PANAMERICANA DE NORMAS TECNICAS. 30:1-019, novembro, 1973.

7. Cozzo,D. Anatomia del leño secundario de las Leguminosas Mimosoi deas y Caesalpinoideas argentinas silvestres y cultivadas.Rev. Inst. Nac. Invest. C. Naturales C. Bot., 2(2):63-290. 1951.

8. MARCHIORI,J.N.C. Estudo anatômico do xilema secundário e da cas ca de algumas espécies dos gêneros Acacia e Mimosa, nativas no Estadó do Rio Grande do Sul. Curitiba, UFPr, 1980. $186 \mathrm{f}$. Tese de Mestrado.

9. RAMBO,B. Estudo comparativo das leguminosas riograndenses. Anais Botânicos, 5:107-184, 1953.

10. RECORD,S.J. \& HESS,R.W. Timbers of the New Wor Zd. New Haven. Yale University Press, 1949. $640 \mathrm{p}$.

Recebido em agosto, 1982; aceito em setembro, 1982. 
